\title{
RESEARCH
}

Open Access

\section{Evaluation of data availability on population health indicators at the regional level across the European Union}

\author{
Claudia Costa ${ }^{1 *}$ D, Ângela Freitas ${ }^{1}$, Iwa Stefanik ${ }^{1}$, Thomas Krafft ${ }^{2}$, Eva Pilot ${ }^{2}$, Joana Morrison $^{3}$ and Paula Santana ${ }^{1}$
}

\begin{abstract}
Background: The ability to measure regional health inequalities across Europe and to build adequate population health indices depends significantly on the availability of reliable and comparable data at the regional level. Within the scope of the EU-funded project EURO-HEALTHY, a Population Health Index (PHI) was built. This model aggregates 39 indicators considered relevant by experts and stakeholders to evaluate and monitor population health on the regional level within the European Union (269 regions). The aim of this research was to assess the data availability for those indicators. As a subsequent aim, an adequate protocol to overcome issues arising from missing data will be presented, as well as key messages for both national and European statistical authorities meant to improve data collection on population health.
\end{abstract}

Methods: The methodology for the study includes three consecutive phases: (i) assessing the data availability for the respective indicators at the regional level for the last year available (ii) applying a protocol for missing data and completing the database and (iii) developing a scoring system ranging from 0 (no data available; worst) to 1 (all data available; best) to evaluate the availability of data by indicator and EU region.

Results: Although the missing data on the set of the PHI indicators was significant, the mean availability score for the EURO-HEALTHY PHI indicators is 0.8 and the regional availability score is 0.7 , which reveal the strength of the indicators as well as the data completeness protocol for missing data.

Conclusions: This study provides a comprehensive data availability assessment for population health indicators from multiple areas of concern, at the EU regional level. The results highlight that the data completeness protocol and availability scores are suitable tools to apply on any indicator's data source mapping. It also raises awareness to the urgent need for sub-national data in several domains and for closing the data gaps between and within countries. This will require policies clearly focused on improving equity between regions and a coordinated effort from the producers of data (the EU28 national statistics offices and EUROSTAT) and the stakeholders who design policies at EU, regional and local level.

Keywords: Population health, Data availability, Indicators, European regions, NUTS, EURO-HEALTHY, Statistics, Policies

\footnotetext{
* Correspondence: claudiampcosta@uc.pt

${ }^{1}$ Centre of Studies in Geography and Spatial Planning (CEGOT), Department

of Geography and Tourism, University of Coimbra, 3004-530 Coimbra,

Portugal

Full list of author information is available at the end of the article
}

(c) The Author(s). 2019 Open Access This article is distributed under the terms of the Creative Commons Attribution 4.0 International License (http://creativecommons.org/licenses/by/4.0/), which permits unrestricted use, distribution, and reproduction in any medium, provided you give appropriate credit to the original author(s) and the source, provide a link to the Creative Commons license, and indicate if changes were made. The Creative Commons Public Domain Dedication waiver (http://creativecommons.org/publicdomain/zero/1.0/) applies to the data made available in this article, unless otherwise stated. 


\section{Background}

Evidence of a widening health gap between EU countries and regions [1-3] requires the ability to measure and monitor indicators that may reveal inequalities [4-6], in line with a public health perspective where populations from the same region share similar conditions that directly or indirectly affect their health [7].

To better understand why some populations are healthier than others and to take action which will improve health and reduce inequalities, monitoring should go far beyond measuring health outcomes [8]. Within the well-known Dahlgren and Whitehead 'social model of health' [9], health inequalities are commonly analysed across several dimensions relating to social, economic and environmental determinants. Many recognise that to reduce inequalities in mortality and morbidity, a shift in health monitoring is required, including the causes and risk factors that continue to cause many communities to lag behind when it comes to the concept of population health in its broadest sense [10-14].

Indicators are well-established monitoring tools, not only for their ability to measure but more specifically because they enable priorities to be set, policies to be formulated and said policies to be evaluated [15-19]. The task of monitoring population health inequalities using indicators from multiple dimensions calls for the availability of spatially disaggregated data at various levels. Having sound data is thus vital to identify gaps and better understand policy impacts, which will enhance informed decision-making [5, 19-26].

The availability of data is regarded as an indispensable standard when measuring health inequalities across countries and regions, as it is frequently identified as the inherent challenge in many EU public health projects, conferences and meetings [13, 23, 25, 27-30]. Sustainable development goals (SDGs) also support the need for data by including an appeal to countries to increase the availability of disaggregated data as part of the goal to strengthen data monitoring and accountability (SDG target 17.18) $[6,8,19]$.

The availability of data is a key component of indicator quality assessment $[8,31,32]$. It is defined as the degree of convenience for users to obtain data and related information [32], as it includes the difficulty level that users may experience when accessing data (e.g. whether the data is public or easy to purchase) and its timeliness (e.g. whether data are regularly updated) [32-34]. Reliability is another key component used, and it refers to 'whether we can trust the data' [32]. Frequently, data quality is described in terms of its completeness (a reliability element), considering the existence or not of a specific data component (e.g. missing values for a year or region). There are different characteristics and ways of assessing indicator data quality reported in the literature: (i) timeliness and frequency of data updates [35], (ii) data availability at a specific geographical scale [36], (iii) relevance of the data according to the user's needs and in terms of indicator definition [37] and (iv) multiple data quality components that are used to build a composite index in which indicator quality is assessed under a scoring system [23, 24, 38, 39].

Over the past four decades, the EU has made substantial progress in developing and improving the data quality of population health indicators at the national level [40] with respect to monitoring policies dealing with the environment [41], road safety [42], housing [43], education [44, 45], social protection and inclusion [46], social cohesion [47, 48] and economic development [49]. The EU Public Health monitoring and reporting system is an example of this effort, along with the multi-phase action 'European Community Health Indicators' (ECHI, ECHI 2 and ECHIM) [26, 28, 36] and the two-phase project 'Health Indicators in the European Regions' (ISARE and I2SARE), which introduced the monitoring at subnational levels [24, 39, 50-52].

Within the EU, the Nomenclature of Territorial Units for Statistics (NUTS) provides a common standard for data collection and statistical purposes, with the NUTS 2 level designation used by the European Commission for the allocation of Cohesion Funds. In this context, having available and comparable data at NUTS 2 level is fundamental to better understand the challenges and opportunities of each region [53]. However, despite various efforts, the lack of regionalised, reliable and comparable data on relevant dimensions to evaluate population health continues to represent a challenge for measuring and monitoring regional health inequalities $[13,24,39,50,51]$.

The goal of the EU research project 'Shaping European policies to promote Health Equity' (EURO-HEALTHY) ${ }^{1}$ was to overcome this lack of health-related data across EU regions. It sought to advance knowledge on policies with the greatest potential to promote health and health equity across EU regions. Underlying this project is the use of multi- and trans-disciplinary approaches and methods to analyse health inequalities. A multidimensional measure-the EURO-HEALTHY Population Health Index (PHI)-was developed to evaluate EU population health across multiple dimensions and at the regional level (269 NUTS $2^{2}$ from the 28 EU countries) and for the reference year of 2014. The underlying approach of this

\footnotetext{
${ }^{1}$ http://www.euro-healthy.eu/

${ }^{2}$ The outermost regions and autonomous cities were not included in EURO-HEALTHY project since many of the indicators are not available for these NUTS 2. This concrete anal is beyond the scope of this study. For more information about the process, see the work by Freitas et al. [54].
} 
project, described as a 'population health approach', defines population health considering both health outcomes and health determinants, and the policies that influence the optimal balance of determinants $[55,56]$. Following this ground-breaking and integrated concept of population health [55-57], the PHI includes multiple indicators of health determinants and health outcomes $[58,59]$. It is based on a hierarchical evaluation model structure $[60,61]$ where the population health of each EU region can be analysed in an aggregated or disaggregated way over a wide range of areas of concern: (i) economic conditions, social protection and security; (ii) education; (iii) demographic change; (iv) lifestyle and health behaviours; (v) physical environment; (vi) built environment; (vii) road safety; (viii) healthcare resources and expenditure; (ix) healthcare performance; and $(x)$ health outcomes [62]. An area of concern reflects broad values of interest to analyse population health and its inequalities, integrating a set of independent evaluation axes (dimensions) which in turn are made operational by means of one or more indicators. The set of indicators in each area of concern was selected via a web-based Delphi process, involving an international and multidisciplinary panel of experts and stakeholders, who stated their views on the extent to which an indicator was relevant for characterising population health [54].

Having a consistent overview of inequalities in health determinants and health outcomes between EU regions requires the completeness of data in all indicators as a main assumption to apply a hierarchical evaluation model structure [63]. The aim of this paper is to assess the data availability of the 39 EURO-HEALTHY PHI indicators considered relevant by experts and stakeholders for evaluating and monitoring population health within the European Union on the regional level. As a subsequent aim, an adequate protocol to overcome the issues of missing data will be presented, as well as key messages to the national and European statistical authorities for improving data collection on population health. Therefore, research reported in this article follows the phase of defining and selecting indicators [54] yet precedes the PHI modelling phase [64] as it is centred on the data collection and data quality assessment of the 39 indicators of the index.

\section{Methods}

\section{Data collection}

The data collection of the indicators to be included in the EURO-HEALTHY PHI was done between November 2015 and July 2016, mainly using major international data sources (EUROSTAT and WHO), considering data for the period 2000-2015 and at the regional level (for all 269 NUTS 2). This geographic scale of analysis was chosen as it is the statistical unit applied by the European
Structural and Investment Funds (ESIF) to determine geographic eligibility for funding and to provide essential opportunities to address and invest in interventions that tackle health inequalities across the EU NUTS 2 regions [65]. Data were stored in a PostgreSQL relational database and made available to the public through a web platform: www.eurohealthydata.uc.pt.

\section{Data completeness}

An exploratory analysis was undertaken for each indicator in order to identify whether there were data gaps considering the geographical scale (NUTS 2 level), reference year (2014) and data source (for each indicator, a reference data source was defined). Figure 1 shows the protocol used to check data availability and to overcome potential cases of missing data. A protocol with eight straight binary questions was applied in case of having no data. It is focused on the three pre-established criteria on data availability: (i) at NUTS 2 level, (ii) for the year 2014 and (iii) from the reference data source. For the cases where it was impossible to retrieve data either from another geographical level or from another year or data source, values could be (i) estimated, considering the population distribution and the values of other NUTS 2 regions within the same country; or (ii) assigned, considering values from other region or country sharing similar geographical, political, social and economic characteristics. Additional file 1 presents a more detailed flowchart of the logical decisions taken to complete the data.

\section{Evaluation criteria and development of a scoring system}

A scoring system, ranging from 0 (data not available) to 1 (all data available), was applied to evaluate overall data availability according to two groups of criteria (Table 1).

Group I includes the criteria related to three mandatory data components (geographical scale, year and data source), while group II corresponds to elective data (estimated or assigned values from a similar NUTS 2 /Country). A higher weight ( 0.7 in 1 ) was attributed to criteria from group I when compared with group II (0.3), given the higher relevance of overcoming data gaps in mandatory data components.

The score was applied to each indicator and to each NUTS 2 region, resulting in two independent scores: the indicator's availability score and the regional availability score. The first revealed which indicator presented more data gaps across EU regions, and the second showed which regions and countries have less data available.

The final score was calculated as follows: 


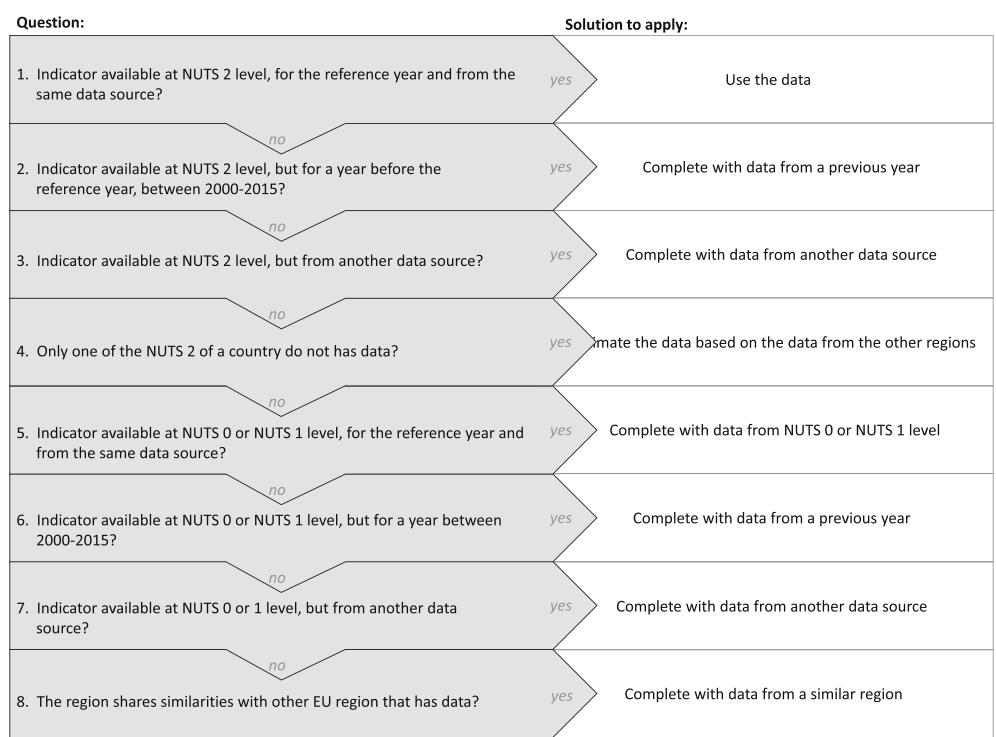

Fig. 1 Data completeness protocol. Each rectangle represents the subsequent binary question used to complete the data. Two answers can be considered: yes or no. If the answer to the question is yes, the white square gives the instruction regarding how to complete the data. If the answer is no, the following question must be made

$$
\begin{aligned}
\text { Final score } & =\left(\frac{\text { Criteria } 1+\text { Criteria2 }+ \text { Criteria3 }}{3} * 0.7\right) \\
& +\left(\frac{\text { Criteria4 }+ \text { Criteria } 5}{2} * 0.3\right)
\end{aligned}
$$

An indicator's availability score of 1 means that the indicator is available for all the regions for the same reference year and the same data source. Similarly, a regional availability score of 1 indicates that all 39 indicators are available for that region for the respective reference year and data source.

The score is analysed in six classes, coloured from orange to green, using the following cut-offs: $0.2,0.4,0.6$, $0.8,0.9$ and 1.0.

\section{Results}

Data availability of Population Health Index indicators

The EURO-HEALTHY Population Health Index integrates 39 indicators that measure population health inequalities across ten areas of concern and 17 dimensions of Health Determinants and Health Outcomes [62]. Data was collected from official statistics, with the EUROSTAT database comprising $80 \%$ of the indicators and the WHO Health for all database (WHO/Europe) a total of 15\% (Table 2). A significant proportion (35\%) was built with derived data (e.g. $\mathrm{PM}_{2.5}$ concentrations; Health personnel; Amenable deaths due to healthcare). When considering the geographical scale, it was found that a significant number of indicators considered relevant to characterise population health are available only at the country level. On average, $74 \%$ of the data from indicators produced at NUTS 2 level is available. For indicators produced at the country level, it is $82 \%$.

Data completeness of the Population Health indicators More than half of the data required to build the Population Health Index was unavailable with respect to the criteria of having NUTS 2 level data for the reference year and from the reference data source. Whenever gaps in the available statistical data were found, other data were used to fill in the gaps (Fig. 2). Most of this data came from a statistical level above the region or from a previous year.

Analysis of the indicator's and regions' availability scores The application of the indicator's availability score to the set of indicators resulted in an overall mean score of 0.79 , ranging from 0.46 to 1.00 (Fig. 3). Additional file 2 presents the scores by area of concern, dimension and indicator by criteria. The analysis showed that the higher mean scores (above 0.90) belong to the dimensions of Employment, Education, and Road safety. The lowest mean scores were found in the dimensions of Water and sanitation (0.50), Lifestyle and health behaviours (0.69) and Healthcare performance (0.68). The lowest mean scores were, for the most part, associated with lack of data at the NUTS 2 level (mean score $=0.46)$ and reference year (mean score $=0.75$ ).

Figure 4 displays the geographical distribution of the regional availability score applied to all 269 NUTS 2 regions. The overall mean score was 0.71 . Although no 
Table 1 Scoring system used to assess the data availability of the EURO-HEALTHY PHI by indicator and Region

\begin{tabular}{|c|c|c|c|c|c|}
\hline \multirow[t]{2}{*}{ Score } & \multicolumn{5}{|c|}{ Regions/Indicators (\%) } \\
\hline & $\begin{array}{l}\text { 1. Data available at } \\
\text { NUTS } 2 \text { level }\end{array}$ & $\begin{array}{l}\text { 2. Data available for } \\
\text { the reference year }\end{array}$ & $\begin{array}{l}\text { 3. Data available from } \\
\text { the same data source }\end{array}$ & 4. Estimated data & $\begin{array}{l}\text { 5. Data from a similar } \\
\text { NUTS } 2 / \text { Country }\end{array}$ \\
\hline 1 & $100 \%$ & $100 \%$ & $100 \%$ & $0 \%$ & $0 \%$ \\
\hline 0.8 & 80-99\% & $80-99 \%$ & 80-99\% & $1-19 \%$ & $1-19 \%$ \\
\hline 0.6 & $60-79 \%$ & $60-79 \%$ & $60-79 \%$ & $20-39 \%$ & $20-39 \%$ \\
\hline 0.4 & $40-59 \%$ & $40-59 \%$ & $40-59 \%$ & $40-59 \%$ & $40-59 \%$ \\
\hline 0.2 & $20-39 \%$ & $20-39 \%$ & $20-39 \%$ & $60-79 \%$ & 60-79\% \\
\hline 0.1 & $1-19 \%$ & $1-19 \%$ & $1-19 \%$ & 80-99\% & 80-99\% \\
\hline 0 & $0 \%$ & $0 \%$ & $0 \%$ & $100 \%$ & $100 \%$ \\
\hline Groups of criteria & \multicolumn{4}{|c|}{ Group I } & Group ॥ \\
\hline
\end{tabular}

Reading example: if an indicator has $85 \%$ of data from the reference year and $22 \%$ of data estimated, the availability score for criteria 2 will be 0.8 and for criteria 4 it will be 0.6

region reached the optimal score of 1 , the map shows that almost all the NUTS 2 (73.2\%) registered high mean scores (above 0.75), with Lithuania and Luxembourg (single-region countries) presenting the highest scores (0.86) followed by regions in Austria, the Czechia and Sweden. At the opposite end of the scale, regions located in Croatia, Ireland, France, Finland, and certain regions of the UK performed worse due to the lack of data in important data assessment criteria.

Similar to the indicator's availability score, regions performing worse are those presenting lack of data at NUTS 2 level (mean score $=0.42$ ) and for the reference year (mean score $=0.74$ ). The analysis by area of concern, available in Additional file 3, revealed that a large number of regions are lacking data in one or more criteria of group 1, namely within Lifestyle and health behaviours, Healthcare performance and Built environment, which yielded the lowest mean scores (0.63, 0.69 and 0.69 , respectively). A high level of internal variability was found in the areas of concern of Healthcare performance and Health outcomes, where within the same country there are regions presenting different mean availability scores.

\section{Discussion}

To our knowledge, this study is the first of its kind to assess data availability of population health indicators for all the $269 \mathrm{EU}$ regions and to identify the adequate protocol to overcome issues with missing data without compromising the quality of the Population Health Index.

Key take-away messages that summarise the main results and their implications for further research and aim to improve data collection at sub-national level across EU will drive the discussion: (1) Data completeness protocol and availability scores are suitable tools to apply on any indicator's data source mapping; (2)
Overcoming missing data issues should be a priority; and (3) Data collection is driven by policy.

\section{Data completeness protocol and availability scores are suitable tools to apply on any indicator's data source mapping}

Indicators are well-established monitoring tools. Thus, applying a data source mapping and analysing their availability is an essential initial step for monitoring population health inequalities [8]. Due to weaknesses identified in this step, indicators are often removed from the analysis [66] or the purpose of the study is compromised [23].

The data collection of the set of 39 EURO-HEALTHY PHI indicators, from 17 different dimensions, encountered challenges, particularly those related to assuring that the indicators were available for all the EU regions and for the same year of analysis. The application of a data completeness strategy allowed for filling in the existent data gaps, resulting in a relatively high score, both at the indicator and regional levels $(0.8$ and 0.7 , respectively, in a range from 0 to 1 ). This protocol, based on single strategies previously defined [19], allowed for the construction of the EURO-HEALTHY Population Health Index. Otherwise, it would not be possible to cover all EU regions and some indicators would be excluded.

The EURO-HEALTHY PHI is seen as a step forward, one which raises awareness of the lack of relevant data to monitor population health and represents the effort to provide an integrated assessment of health (considering indicators of Health Outcomes and Health Determinants) and a geographically meaningful tool allowing for the analysis and comparison of health across all regions of the 28 EU countries in a specific year. The final purpose underlying the development of this tool is to use its capabilities to inform regional policies by providing evidence on relevant dimensions where policy action has high potential for 
Table 2 Data availability for the EURO-HEALTHY PHI Indicators, according to the geographical scale and reference year

\begin{tabular}{|c|c|c|c|c|c|c|c|}
\hline \multirow[t]{2}{*}{ Component } & \multirow[t]{2}{*}{ Dimension } & \multirow[t]{2}{*}{ Indicator } & \multirow[t]{2}{*}{ Source } & \multirow[t]{2}{*}{$\begin{array}{l}\text { Geographical } \\
\text { scale }\end{array}$} & \multirow[t]{2}{*}{$\begin{array}{l}\text { Reference } \\
\text { year }\end{array}$} & \multicolumn{2}{|c|}{$\begin{array}{l}\text { Data availability } \\
(\%)\end{array}$} \\
\hline & & & & & & $\begin{array}{l}\text { NUTS2 } \\
(n=269)\end{array}$ & $\begin{array}{l}\text { Country } \\
(N=28)\end{array}$ \\
\hline \multirow{30}{*}{$\begin{array}{l}\text { Health } \\
\text { Determinants }\end{array}$} & \multicolumn{7}{|c|}{ Area of concern: Economic conditions, social protection and security } \\
\hline & \multirow[t]{2}{*}{ Employment } & Unemployment rate (\%) & EUROSTAT & NUTS 2 & 2014 & 99.6 & \\
\hline & & $\begin{array}{l}\text { Long-term unemployment rate-12 months } \\
\text { and more (\%) }\end{array}$ & EUROSTAT & NUTS 2 & 2014 & 97.4 & \\
\hline & \multirow{3}{*}{$\begin{array}{l}\text { Income and } \\
\text { living } \\
\text { conditions }\end{array}$} & $\begin{array}{l}\text { Disposable income of private households per } \\
\text { capita (Euro per inhabitant) }\end{array}$ & EUROSTAT & NUTS 2 & 2012 & 99.3 & \\
\hline & & People at risk of poverty or social exclusion (\%) & EUROSTAT & NUTS 2 & 2014 & 21.9 & \\
\hline & & Disposable income ratio_-S80/S20 (ratio) & EUROSTAT & Country & 2014 & & 92.9 \\
\hline & $\begin{array}{l}\text { Social } \\
\text { protection }\end{array}$ & Expenditure on care for elderly (\% of GDP) & EUROSTAT & Country & 2008 & & 96.4 \\
\hline & Security & $\begin{array}{l}\text { Crimes recorded by the police per } \\
100.000 \text { inhabitants }\end{array}$ & $\begin{array}{l}\text { EURO-HEALTHY/ } \\
\text { EUROSTAT }\end{array}$ & NUTS 2 & 2010 & 65.4 & \\
\hline & \multicolumn{7}{|c|}{ Area of concern: Education } \\
\hline & \multirow[t]{2}{*}{ Education } & $\begin{array}{l}\text { Population aged } 25-64 \text { with upper secondary } \\
\text { or tertiary education attainment (\%) }\end{array}$ & EUROSTAT & NUTS 2 & 2014 & 99.3 & \\
\hline & & Early leavers from education and training (\%) & EUROSTAT & NUTS 2 & 2014 & 93.3 & \\
\hline & \multicolumn{7}{|c|}{ Area of concern: Demographic change } \\
\hline & \multirow[t]{2}{*}{ Ageing } & $\begin{array}{l}\text { Rate of older people at risk of poverty-aged } \\
65 \text { years or over (\%) }\end{array}$ & EUROSTAT & Country & 2013 & & \multirow[t]{2}{*}{92.9} \\
\hline & & Ageing index (ratio) & $\begin{array}{l}\text { EURO-HEALTHY/ } \\
\text { EUROSTAT }\end{array}$ & NUTS 2 & 2014 & 100.0 & \\
\hline & \multicolumn{7}{|c|}{ Area of concern: Lifestyle and health behaviours } \\
\hline & \multirow{4}{*}{$\begin{array}{l}\text { Lifestyle and } \\
\text { health } \\
\text { behaviours }\end{array}$} & Adults who are obese (\%) & EUROSTAT & Country & 2008 & & 96.4 \\
\hline & & Daily smokers—aged 15 and over (\%) & OECD & Country & 2013 & & 35.7 \\
\hline & & $\begin{array}{l}\text { Pure alcohol consumption-aged } 15 \text { and } \\
\text { over (litres per capita) }\end{array}$ & HFA-DB & Country & 2013 & & 28.6 \\
\hline & & Live births by mothers under age of 20 (\%) & $\begin{array}{l}\text { EURO-HEALTHY/ } \\
\text { EUROSTAT }\end{array}$ & NUTS 2 & 2013 & 85.9 & \\
\hline & \multicolumn{7}{|c|}{ Area of concern: Physical environment } \\
\hline & \multirow[t]{3}{*}{ Pollution } & $\begin{array}{l}\text { Annual mean of the daily PM2.5 } \\
\text { concentrations }\left(\mu \mathrm{g} / \mathrm{m}^{3}\right)\end{array}$ & $\begin{array}{l}\text { EURO-HEALTHY/ } \\
\text { EEA }\end{array}$ & NUTS 2 & 2011 & 98.9 & \\
\hline & & $\begin{array}{l}\text { Annual mean of the daily PM10 } \\
\text { concentrations }\left(\mu \mathrm{g} / \mathrm{m}^{3}\right)\end{array}$ & $\begin{array}{l}\text { EURO-HEALTHY/ } \\
\text { EEA }\end{array}$ & NUTS 2 & 2011 & 98.9 & \\
\hline & & $\begin{array}{l}\text { Greenhouse } \mathrm{Gas}(\mathrm{GHG}) \text {, total tonnes of } \mathrm{CO}_{2} \text { eq. } \\
\text { emissions per annum per capita }\end{array}$ & EUROSTAT & Country & 2012 & & 100.0 \\
\hline & \multicolumn{7}{|c|}{ Area of concern: Built environment } \\
\hline & \multirow{3}{*}{$\begin{array}{l}\text { Housing } \\
\text { conditions }\end{array}$} & Average number of rooms per person & EUROSTAT & NUTS 2 & 2014 & 35.3 & \\
\hline & & Households without indoor flushing toilet (\%) & $\begin{array}{l}\text { EURO-HEALTHY/ } \\
\text { EUROSTAT }\end{array}$ & NUTS 2 & 2011 & 97.4 & \\
\hline & & Households without central heating (\%) & $\begin{array}{l}\text { EURO-HEALTHY/ } \\
\text { EUROSTAT }\end{array}$ & NUTS 2 & 2011 & 96.7 & \\
\hline & \multirow[t]{2}{*}{$\begin{array}{l}\text { Water and } \\
\text { sanitation }\end{array}$} & $\begin{array}{l}\text { Population connected to wastewater } \\
\text { treatment plants }\end{array}$ & EUROSTAT & Country & 2014 & & 25.0 \\
\hline & & Population connected to public water supply & EUROSTAT & NUTS 2 & 2013 & 14.5 & \\
\hline & $\begin{array}{l}\text { Waste } \\
\text { management }\end{array}$ & Recycling rate of municipal waste (\%) & EUROSTAT & Country & 2013 & & 100.0 \\
\hline
\end{tabular}


Table 2 Data availability for the EURO-HEALTHY PHI Indicators, according to the geographical scale and reference year (Continued)

\begin{tabular}{|c|c|c|c|c|c|c|c|}
\hline \multirow[t]{2}{*}{ Component } & \multirow[t]{2}{*}{ Dimension } & \multirow[t]{2}{*}{ Indicator } & \multirow[t]{2}{*}{ Source } & \multirow[t]{2}{*}{$\begin{array}{l}\text { Geographical } \\
\text { scale }\end{array}$} & \multirow[t]{2}{*}{$\begin{array}{l}\text { Reference } \\
\text { year }\end{array}$} & \multicolumn{2}{|c|}{$\begin{array}{l}\text { Data availability } \\
(\%)\end{array}$} \\
\hline & & & & & & $\begin{array}{l}\text { NUTS2 } \\
(n=269)\end{array}$ & $\begin{array}{l}\text { Country } \\
(N=28)\end{array}$ \\
\hline & \multicolumn{7}{|c|}{ Area of concern: Road safety } \\
\hline & \multirow[t]{2}{*}{ Road safety } & $\begin{array}{l}\text { Victims in road accidents_-injured and killed, } \\
\text { per 100,000 inhabitants }\end{array}$ & $\begin{array}{l}\text { EURO-HEALTHY/ } \\
\text { EUROSTAT }\end{array}$ & NUTS 2 & 2013 & 91.5 & \\
\hline & & $\begin{array}{l}\text { Fatality rate due to road traffic accidents, per } \\
1000 \text { victims }\end{array}$ & $\begin{array}{l}\text { EURO-HEALTHY/ } \\
\text { EUROSTAT }\end{array}$ & NUTS 2 & 2013 & 91.5 & \\
\hline & \multicolumn{7}{|c|}{ Area of concern: Healthcare resources and expenditure } \\
\hline & \multirow{2}{*}{$\begin{array}{l}\text { Healthcare } \\
\text { resources }\end{array}$} & Medical doctors, per 100,000 inhabitants & EUROSTAT & NUTS 2 & 2013 & 61.4 & \\
\hline & & $\begin{array}{l}\text { Health personnel (nurses and midwives, } \\
\text { dentists, pharmacists and physiotherapists), } \\
\text { per } 100,000 \text { inhabitants }\end{array}$ & $\begin{array}{l}\text { EURO-HEALTHY/ } \\
\text { EUROSTAT }\end{array}$ & NUTS 2 & 2013 & 44.6 & \\
\hline & \multirow[t]{3}{*}{$\begin{array}{l}\text { Healthcare } \\
\text { expenditure }\end{array}$} & $\begin{array}{l}\text { Total health expenditure (THE), PPP\$ per } \\
\text { capita, WHO estimates }\end{array}$ & HFA-DB & Country & 2013 & & 100.0 \\
\hline & & $\begin{array}{l}\text { Private households' out-of-pocket on health as } \\
\text { percentage of total health expenditure (THE) }\end{array}$ & HFA-DB & Country & 2013 & & 100.0 \\
\hline & & $\begin{array}{l}\text { Public expenditure on health, PPP\$ per capita, } \\
\text { WHO estimates }\end{array}$ & HFA-DB & Country & 2013 & & 100.0 \\
\hline & \multicolumn{7}{|c|}{ Area of concern: Healthcare performance } \\
\hline & \multirow[t]{2}{*}{$\begin{array}{l}\text { Healthcare } \\
\text { performance }\end{array}$} & $\begin{array}{l}\text { Hospital discharges due to diabetes, } \\
\text { hypertension and asthma, per 100,000 } \\
\text { inhabitants }\end{array}$ & $\begin{array}{l}\text { EURO-HEALTHY/ } \\
\text { EUROSTAT }\end{array}$ & NUTS 2 & 2013 & 32.7 & \\
\hline & & $\begin{array}{l}\text { Amenable deaths due to health care- } \\
\text { standardised death rate, per 100,000 } \\
\text { inhabitants }\end{array}$ & $\begin{array}{l}\text { EURO-HEALTHY/ } \\
\text { EUROSTAT }\end{array}$ & NUTS 2 & $2011-13$ & 38.3 & \\
\hline \multirow{7}{*}{$\begin{array}{l}\text { Health } \\
\text { Outcomes }\end{array}$} & \multicolumn{7}{|c|}{ Area of concern: Health outcomes } \\
\hline & \multirow[t]{3}{*}{ Mortality } & Life expectancy at birth (years) & EUROSTAT & NUTS 2 & 2013 & 85.9 & \\
\hline & & Infant mortality, per 1000 live births & EUROSTAT & NUTS 2 & $2011-13$ & 99.6 & \\
\hline & & $\begin{array}{l}\text { Preventable deaths - standardised death rate, } \\
\text { per } 100,000 \text { inhabitants }\end{array}$ & $\begin{array}{l}\text { EURO-HEALTHY/ } \\
\text { EUROSTAT }\end{array}$ & NUTS 2 & $2011-13$ & 24.9 & \\
\hline & \multirow[t]{3}{*}{ Morbidity } & Self-perceived health less than good (\%) & EUROSTAT & Country & 2013 & & 100.0 \\
\hline & & $\begin{array}{l}\text { Age-standardised disability-adjusted life year } \\
\text { (DALY) rates }\end{array}$ & HFA-DB & Country & 2012 & & 100.0 \\
\hline & & Low birth-weight (\%) & $\begin{array}{l}\text { EURO-HEALHTY/ } \\
\text { HFA-DB/ } \\
\text { EUROSTAT }\end{array}$ & Country & 2013 & & 64.3 \\
\hline
\end{tabular}

For indicators collected directly from official data sources, the name of the statistics producer appears in the 'source' column. For the indicators derived from data collected from official data sources, EURO-HEALTHY and the name of the statistics producer appear in the 'source' column

The table presents two different things: (1) the PHI model structure with the PHI's components, areas of concern, dimensions and indicators; and (2) General information about the indicators as to where they are available

reducing inequalities in health between regions [62]. As it is widely understood in the public health community, no data, no knowledge, no action [67]. When developing an index, obstacles and constraints arise when dealing with the availability of data on indicators considered relevant to inform policies.

Through the PHI model, the EURO-HEALTHY project already defined the framework for monitoring population health in Europe. So, for the future, it is important to continue evaluating data availability and discussing the data collection process at EU level.

\section{Mind the health gap: why overcoming missing data should be a priority}

The first assumption of a good monitoring system of health inequalities across Europe is to have good quality data, which is available and comparable between different countries and regions [8]. According to the literature, having sound data is vital to identify gaps and better understand policy impacts, which enhances informed decision-making [5, 19-26]. This is particularly challenging when there are countries with different political attitudes towards health inequalities 


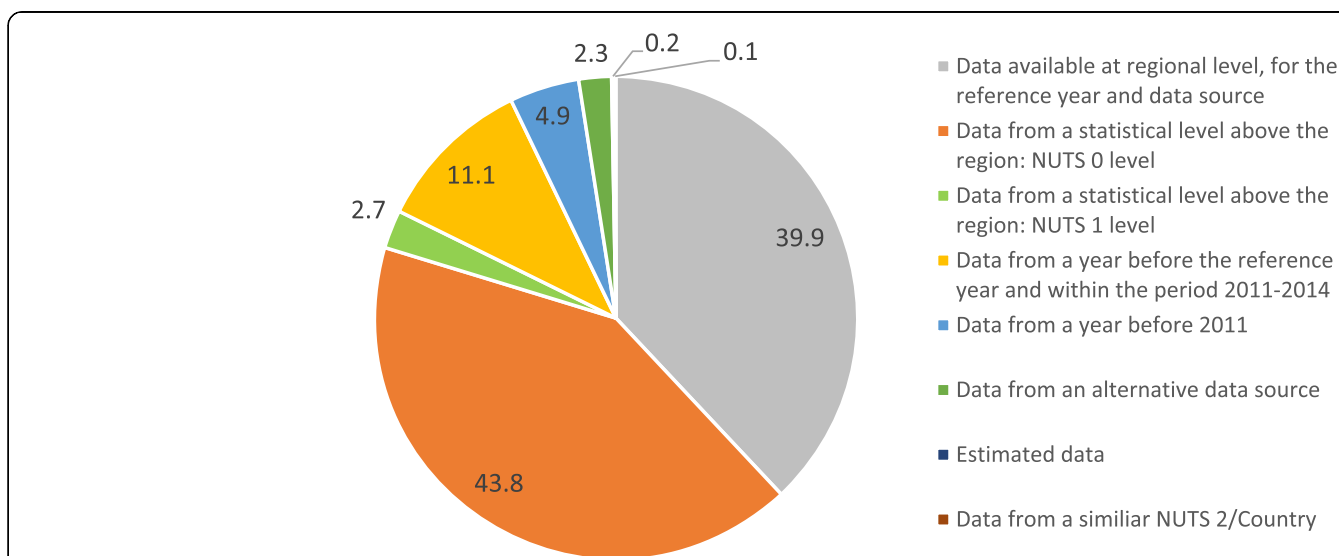

Fig. 2 Source of the data required to complete the Population Health Indicators. The graph represents how the missing data was completed and the share of each solution used to complete the data

within the $\mathrm{EU}$, from measuring health inequalities to recognising disparities and their consequences on health [68].

The analysis made by dimension revealed significant differences in the indicator's availability scores, ranging from 0.95 on Road safety (almost all data were available on its indicators) to 0.50 on Water and sanitation (with huge data gaps at the geographical level of NUTS 2).

Availability at NUTS 2 level was the criteria achieving the lowest score, particularly for the indicators of Built environment, Lifestyle and health behaviours and Healthcare performance. Four reasons were identified: (1) indicators' availability only at the country level, (2) isolated regions with small number of people and specific monitoring systems, (3) lack of adherence between the local and regional monitoring services and the administrative levels supported by EUROSTAT and (4) absence of cohesion between countries on monitoring topics.

A significant number of indicators considered relevant to monitor population health in the $\mathrm{EU}$ at regional level are only available at country level. Most of them belong to the European Core Health Indicators (ECHI), which includes the indicators considered as relevant for monitoring national progress in relation to Europe 2020 objectives [69]. Yet, at the sub-national level, they are not routinely collected or even readily available $[24,28]$. This is due to a centralised health sector (e.g. health expenditure) or to the data collection process, based on self-reports, developed for a sample representative of the country (e.g. morbidity indicators) and often not comparable for benchmarking (e.g. lifestyle and health behaviour) $[24,36,39]$. For instance, only recently have EU member states been obliged to collect data on health status, along with the provision of healthcare, health determinants and socio-economic conditions of their populations, in the context of the European Health Interview Survey (EHIS) [46, 70]. Prior to this, most countries collected their own data on lifestyles and health behaviours at the regional level through $\mathrm{Na}$ tional Health Surveys. Still, countries decide when to collect this data and which indicators are to be collected and disseminated. Therefore, the data present a large variation in terms of the reporting year, and a lack of harmonisation and comparability between countries (e.g. different definition of the survey sampling), so it is not possible to use these National Health Surveys.

Our study also found NUTS 2 regions without data on dimensions with high availability scores like Education and Employment, requiring them to be completed with estimated data. These often corresponded to isolated areas with low number of inhabitants and specific monitoring systems adapted to the local circumstances (e.g. Finland).

The lack of adherence to the EU statistical levels is visible in indicators related with healthcare resources (e.g. Medical doctors, Health personnel) and outcomes (e.g. Hospital discharges) which had to be completed with values at country level. In the past, the ECHI project already identified the performance of healthcare systems as one of the domains requiring extra investment on developing comparable statistics at the regional level [28], and the ISARE project even suggested the use of different geographical levels in order to analyse health data in Europe [24]. Differences between the NUTS classification, used by the EUROSTAT, and the national health regions explain this [24, 39]. According to Wilkinson and colleagues [24], there is a lack of adherence of the health regions to the NUTS level in the 'old' countries of the 


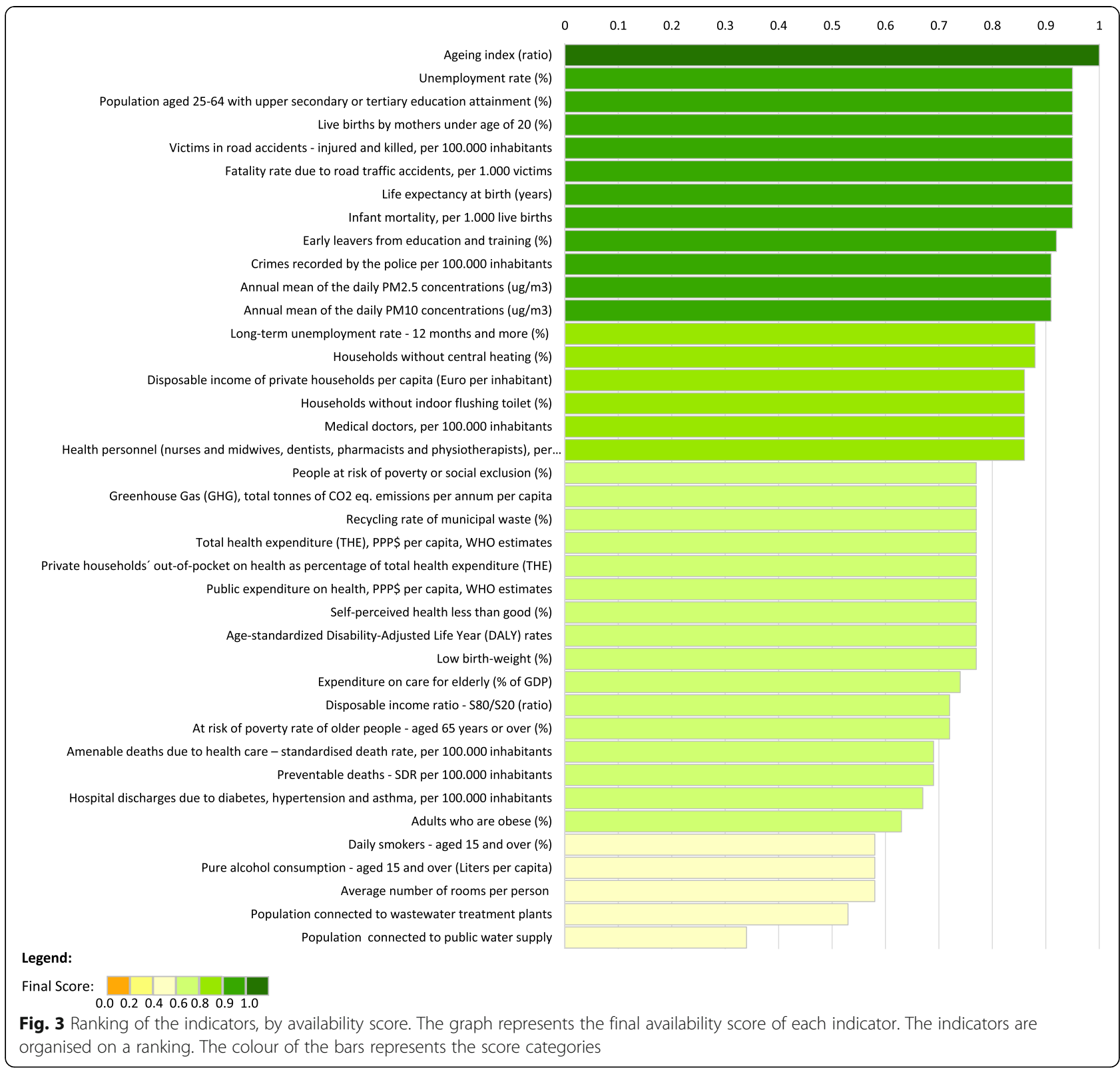

European Union, motivated by a decentralised system where policy-making is at the local level (e.g. Germany and the UK) [71].

The absence of agreement between countries also compromises some indicators associated with built environment and access to water and sanitation. Although EUROSTAT launched a new platform to give access to census data, the European Census Hub tool, few topics are covered due to differences between countries. For instance, the water and sanitation indicators (scores of 0.53 and 0.46 ) are not yet available via the European Census Hub database due to the lack of comparability across EU countries. Even where data for NUTS 2 level is theoretically available, which is the case of Population connected to public water supply, data at this level appear only to be available for the regions of Eastern European countries, possibly because they were the last to become part of the EU and required substantial investment in improving the levels on access to basic infrastructures. Most of the 'old' EU countries already have very high shares of the population connected to water and wastewater treatment plants, which in turn, could potentially explain the cases of missing data for the recent years.

In fact, the temporal scale of the data was the second most applied criteria in order to complete missing data. Countries like Belgium, Denmark and Sweden present 


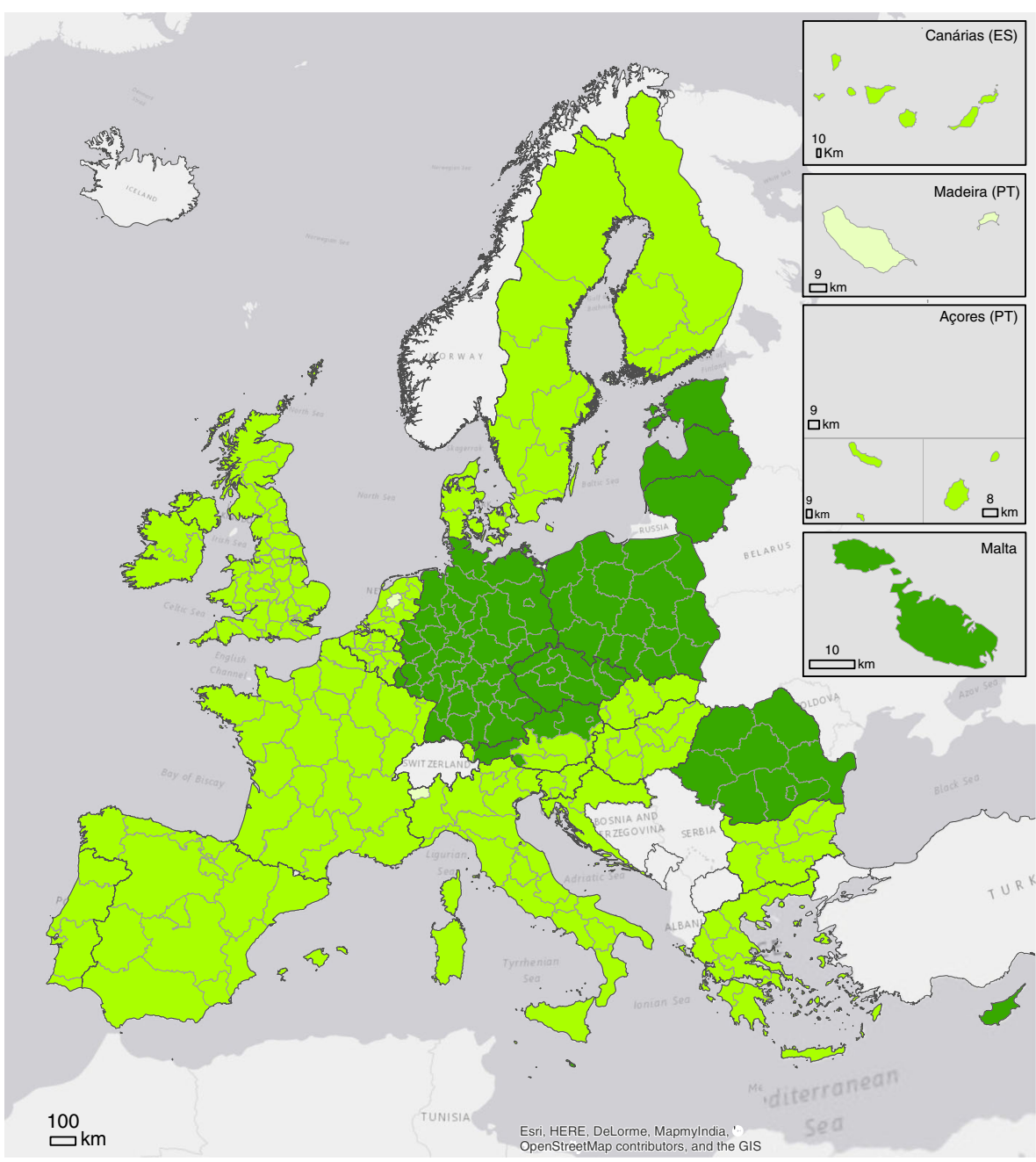

EURO-HEALTHY PHI indicators availability score

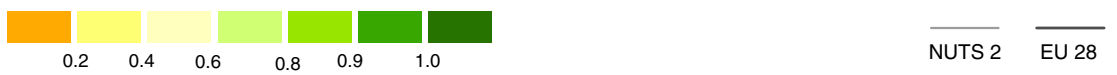

Fig. 4 Map of overall regional availability score in the EU28. The colours represent the score achieved by each region within EU28 NUTS 2 level. Green colours represent higher availability. Orange colours represent lower availability

data from healthcare resources from a year before the reference year of this study. This is linked to EUROSTAT's data delivery: EU countries may provide their annual data at any time between 18 to 24 months after the reporting period, so EUROSTAT quite often releases its data for a new year, whereas most countries haven not reported it yet.

Finally, the regional availability score also reveals that none of the EU regions presented data for all 39 indicators according to the criteria, that is, for the regional level (NUT 2 level), for the reference year and for the same data source. This score ranges from 0.91 on Road safety (almost all regions available according to the criteria) to 0.63 on Lifestyles and health behaviours (with most indicators at country level). Surprisingly, the lowest scores identified in our study were found in countries from Central and Western Europe (e.g. France). However, a previous study considering data availability at country level concluded that data availability did not differ between the EU-15 and the EU-27 [36].

\section{Data collection is driven by policy}

Within the European Union, data collection is driven by a policy derived from an international or EC initiative with focus on performance measurement and resultsbased policy making, stating the framework of indicators to be collected and for which scale [19]. 
Road safety, Education, Employment and Pollution dimensions reveal indicators with good data availability (above 0.86), which is linked to EU policy development over the years requiring monitoring data at sub-national level $[42,45,50,72]$ to define policies able, for example, to decrease road accidents, reduce the number of early school leavers and achieve high educational levels [44, 73, 74]. The same is revealed by the mortality dimension. EUROSTAT has a long tradition of providing access to mortality indicators [24] due to a number of important EU policies deploying mortality indicators for planning actions, and for monitoring and evaluating programmes, notably in the health, social and economic fields $[28,75]$.

Still, the argument of EU policy development driving data collection and comparability at sub-national levels do not seem to apply to all policies. Although it is recognisable by the European Commission (EC) that the regional and local level have a crucial role to play in decreasing Greenhouse gas emissions [76], promoting social inclusion $[46,77]$ and tackling obesity [70], the data collection occurs at the country level. Regarding the monitoring of Greenhouse gas emissions, a region's lack of capacity to efficiently monitor and observe greenhouse gases is an issue [78]. As for measuring material deprivation and obesity, the EC focuses on analysing demography and social issues at the level of the individual rather than by place of residence, so the data collection frequently relies on survey samples representative only of the country, which limits the capacity to evaluate poverty and obesity issues at sub-national levels [5, 70, 79].

Other policies focused on traffic noise, contaminated sites and exposure to flooding, with impact on population health, do not explicitly mandate the level for data collection [80-82], meaning that such environmental hazards are poorly documented and constitute a significant limitation when informing regional policies.

\section{Strengths and limitations}

Despite the many pitfalls associated with having 39 indicators available for all NUTS 2 regions and for the reference year, this study advances knowledge on the potential of producing a multidimensional database of comparable population health indicators at the EU regional level. The application of a structured and transparent methodology allowed for missing data to be completed, thus adding validity to the database used to build the population health index.

However, six limitations can be identified in this study.

First, the indicators are updated on a regular basis, so the results presented may be seen as outdated rather quickly, meaning that the process has to be frequently updated.

Second, the results of this paper should be interpreted with caution; the regions differ considerably in population size. The NUTS regulation allows for a wide range, between the minimum (800,000 inhabitants) and maximum ( 3 million) threshold for NUTS 2 regions. This range is simply intended for guidance; there are some NUTS 2 regions with a population less than 30,000 inhabitants (Aland in Finland) and others with over 12 million inhabitants (île de France in France).

Third, the number of regions in each country contributed substantially to the results, which may represent an important limitation of this study. This happened in cases of data absence for countries with many regions and in single-region countries. Thus, the lack of data at the regional level for the UK (40 NUTS 2) corresponded to almost $15 \%$ of missing data at EU level.

Fourth, the weight assigned to each group of criteria has a significant impact on the final score, so different weights would lead to distinct results. Still, the relevance of each criteria is different for the robustness of the PHI, so the final score had to reflect this.

Finally, although we argue that all the indicators included in the PHI should be collected at the regional level and all the data gaps should be tackled, we do not make any reference to the high costs that collecting all this data would entail.

\section{Further research and recommendations}

This article is an attempt to build a bridge between the scientific community and policy-makers. The identification of data gaps at the regional level (NUTS 2) in several areas of concern and dimensions of population health has the potential to inform priorities for data collection and harmonisation. In addition, the findings from the study can (i) advance future research about compiling data for measuring population health under a holistic and multidimensional approach, including health outcomes and health determinants and (ii) highlight important recommendations for both National and European statistical authorities. In addition, they might raise the awareness required to apply the PHI to the entire region of Europe, which would be of relevance in all sub-regions shared across borders within and outside the EU28, where health is co-determined by factors relevant across the borders.

The identification of major data gaps within indicators considered relevant to evaluate population health (included in the PHI) is a call for attention to any future (re)definition of the European statistical system which considers the indicators where data collection is required at the regional level (e.g. built environment). The evaluation of the effectiveness of regional policies in shaping 
important health determinants demands information and evidence at the sub-national level.

Awareness of the relevance of this data at the regional level can help encourage researchers and other stakeholders to advocate for data collection at several geographical levels. The data availability score developed in this study may have the potential to become a point of departure for decision-makers to assess the quality of the data being used in the monitoring of important indicators which contribute to the improvement of population health.

Finally, a data availability score of 1 would be the goal for all indicators and regions. This would require better coordination on the part of the statistics authorities of each Member State and EUROSTAT to develop highquality, harmonised and comparable statistics for different geographical levels.

\section{Conclusions}

The challenges encountered in this study underscore the urgent need to close 'data gaps' as a condition for closing the 'health gaps' within relevant population health indicators between and within EU countries. This is particularly true for health determinants, which are fundamental to inform policy and monitor its effectiveness. This need is mentioned in several international documents and reports, namely the Health 2020 framework: The European policy for health and well-being, the European Health Report 2015 [79], the discussion paper on Closing the gap: policy into practice on Social Determinants of Health [13] and the Transforming our World: The 2030 Agenda for Sustainable Development $[6,8]$. These documents highlight the relevance of the availability of indicators measuring well-being and inequities in population health associated with social determinants, especially at the sub-national level. Public health knowledge on the importance of risk factors and health determinants may be a difficult task in data collection, providing the same attention that is given to monitoring mortality. As a matter of fact, the study reveals that there is still room for improvement.

Notwithstanding, a clear prior statement on tackling regional inequalities within each policy is essential, as the data collection is linked to the policy-making process followed at EU level. Data at the sub-national level is essential for implementing policies that address inequities, but also for better decision-making and accountability at the local level. To ensure that this data will serve as the catalyst for action, it is important to increase awareness that sub-national data promotes better understanding of the baseline levels, information to design effective policies and an explanation of the potential impact of policies. Therefore, it is crucial that progress be made on the link between social determinants, policies and health inequities.

\section{Additional files}

Additional file 1: Data completeness flowchart. Flowchart considered to complete the missing data on the Population Health Indicators. The first step corresponds to the identification of the geographical level the indicator is. If it is available at regional level, the option A must be considered. If it is available at country level, the option B must be applied. (PDF $671 \mathrm{~kb}$ )

Additional file 2: Indicator availability score of the EURO-HEALTHY $\mathrm{PHI}$ indicators. Table with the availability scores from each indicator and dimension by criteria. (PDF 487 kb)

Additional file 3: Map of regional availability score in the EU, by area of concern. Figure with the regional availability score of each area of concern. (PDF $1870 \mathrm{~kb}$ )

\section{Abbreviations}

EC: European Commission; ECHI: Project 'European Community Health Indicators'; ECHIM: Project 'European Community Health Indicators Monitoring'; EEA: European Environment Agency; EU: European Union; EUROHEALTHY: Project 'Shaping EUROpean policies to promote HEALTH equitY'; ISARE: Project 'Health Indicators in the European Regions'; MEHM: Minimum European Health Module; NUTS: Nomenclature of Territorial Units for Statistics; OECD: Organisation for Economic Co-operation and Development; OMC: Open Method of Coordination; PHI: Population Health Index

\section{Acknowledgements}

The authors would like to acknowledge Ricardo Almendra, Adriana Loureiro, Luís Monteiro, Aida Tavarees and Cátia Leal for their support in the data collection process. Moreover, they would like to acknowledge Klea Katsouyanni, Sophia Rodopoulou, Stéphane Rican, Quentin Tenailleu, Sotiris Vardoulakis, Sani Dimitroulopoulou and Christina Mitsakou for their support in data collection at their individual national statistics bureaus; to Michal Tkac who lent support for the methodology needed to estimate the missing data; to Scott Culp for English review services, and the reviewers for their careful reading of our manuscript and their many insightful comments and suggestions.

\section{Funding}

This publication was developed in Centre of Studies in Geography and Spatial Planning (CEGOT) and supported by National Funds through the Portuguese Foundation for Science and Technology (FCT) under Grant UID/ GEO/04084/2019, by the EURO-HEALTHY project (Shaping EUROpean policies to promote HEALTH equity) that received funding from the European Union's Horizon 2020 research and innovation programme under Grant Agreement No 643398.

\section{Availability of data and materials}

All the indicators collected during the EURO-HEALTHY study are available via the eurohealthy data platform, available to the public through a personal password. The link for the platform is www.eurohealthydata.uc.pt.

\section{Authors' contributions}

All authors made substantial contributions to the conception and drafting of the manuscript. All authors read and approved the final manuscript.

Ethics approval and consent to participate

Not applicable.

Consent for publication

Not applicable.

\section{Competing interests}

The authors declare that they have no competing interests.

\section{Publisher's Note}

Springer Nature remains neutral with regard to jurisdictional claims in published maps and institutional affiliations. 


\section{Author details}

${ }^{1}$ Centre of Studies in Geography and Spatial Planning (CEGOT), Department of Geography and Tourism, University of Coimbra, 3004-530 Coimbra, Portugal. ${ }^{2}$ Faculty of Health, Medicine and Life Sciences (FHML), Care and Public Health Research Institute (CAPHRI), Department of Health, Ethics and Society, Maastricht University, Maastricht, The Netherlands. ${ }^{3}$ Research Department of Epidemiology and Public Health, University College London, London, UK.

Received: 2 March 2018 Accepted: 22 July 2019

Published online: 07 August 2019

\section{References}

1. Mackenbach J. Health inequalities: Europe in profile. COI for the Department of Health 2006. Available from: https://www.who.int/social_ determinants/media/health_inequalities_europe.pdf

2. Santana P, Costa C, Cardoso G, Loureiro A, Ferrão J. Suicide in Portugal: spatial determinants in a context of economic crisis. Health Place. 2015;35:85-94. Elsevier. Available from: https://www.ncbi.nlm.nih.gov/pubmed/26277771

3. Shaw M, Orford S, Brimblecombe N, Dorling D. Widening inequality in mortality between 160 regions of 15 European countries in the early 1990 s. Soc Sci Med. 2000;50:1047-58. Elsevier. Available from: http://www.ncbi.nlm. nih.gov/pubmed/10714926. Cited 8 Dec 2016

4. Ritsatakis A, Makara P. Gaining health. Analysis of policy development in European countries for tackling noncommunicable diseases. Geneva: World Health Organization; 2009. Available from: http://www.euro.who.int/en/ publications/abstracts/gaining-health-analysis-of-policy-development-ineuropean-countries-for-tackling-noncommunicable-diseases

5. Stewart K. Monitoring social inclusion in Europe's regions. J Eur Soc Policy. 2003:13:335-56. SAGE PublicationsLondon, Thousand Oaks and New Delhi. Available from: http://journals.sagepub.com/doi/10.1177/09589287030134 002. Cited 2 May 2017

6. Hosseinpoor AR, Bergen N. Area-based units of analysis for strengthening health inequality monitoring. Bull World Health Organ. 2016;94:856-8. World Health Organization. Available from: https://www.ncbi.n/m.nih.gov/pmc/ articles/PMC5096344/

7. Hosseinpoor AR, Bergen N, Barros AJD, Wong KLM, Boerma T, Victora CG. Monitoring subnational regional inequalities in health: measurement approaches and challenges. Int J Equity Health. 2016;15:18. BioMed Central. Available from: http://equityhealthj.biomedcentral.com/articles/10.1186/s12 939-016-0307-y

8. World Health Organization. National health inequality monitoring: a step-bystep manual. World Health Organization, 2017. Available from: https://www. who.int/gender-equity-rights/knowledge/national-health-inequalitymonitoring/en/

9. Dahlgren $G$, Whitehead M. Policies and strategies to promote social equity in health: Arbetsrapport 2007:14, Institute for Futures Studies. Available from: http://ideas.repec.org/p/hhs/ifswps/2007 014.html

10. Braveman $P$, Gottlieb $L$. The social determinants of health: it's time to consider the causes of the causes. Public Health Rep. 2014;129(Suppl 2):1931. SAGE Publications. Available from: http://www.ncbi.nlm.nih.gov/ pubmed/24385661. Cited 12 Dec 2017

11. Marmot M, Friel S, Bell R, Houweling TA, Taylor S, Commission on Social Determinants of Health. Closing the gap in a generation: health equity through action on the social determinants of health. Lancet. 2008; 8; 372(9650):1661-9. The Lancet. Available from: https://www.ncbi.nlm.nih.gov/ pubmed/18994664

12. World Health Organization. Targets and beyond-reaching new frontiers in evidence. 2015. Available from: http://www.euro.who.int/_data/assets/pdf_ file/0006/288645/European-health-report-2015-full-book-en.pdf

13. World Health Organization. Closing the gap: policy into practice on social determinants of health: World Health Organization; 2011. Available from: http://www.who.int/sdhconference/Discussion-paper-EN. pdf. Cited 10 Jan 2018

14. Graham H. Social determinants and their unequal distribution: clarifying policy understandings. Milbank Q. 2004;82:101-24. Milbank Memorial Fund. Available from: http://www.ncbi.nlm.nih.gov/pubmed/15016245. Cited 6 Mar 2019

15. von Schirnding Y. Health in sustainable development planning: the role of indicators. World Health Organization; 2002. Available from: https://apps. who.int/iris/handle/10665/67391
16. Rosenkötter N, Achterberg PW, van Bon-Martens MJH, Michelsen K, van Oers HAM, Brand $\mathrm{H}$. Key features of an EU health information system: a concept mapping study. Eur J Public Health. 2015 Feb;26(1):65-70. Oxford Journals. Available from: https://www.ncbi.nlm.nih.gov/pubmed/25944870

17. Salmi L-R, Barsanti S, Bourgueil Y, Daponte A, Piznal E, Ménival S, et al. Interventions addressing health inequalities in European regions: the AIR project. Health Promot Int. 2015. Oxford Journals. Available from: http:// www.ncbi.nlm.nih.gov/pubmed/26508665. Cited 3 May 2017

18. Boesch A, Montmollin A, Kulig A, Palm V, Willi V, Zuinen N. Getting messages across using indicators. A handbook based on experiences from assessing Sustainable Development Indicators: EUROSTAT; 2014 Available from: http://ec.europa.eu/eurostat/documents/3859598/59364 09/KS-GQ-12-001-EN.PDF/c47039bd-c026-4d99-a819-135b5e4c1da4 ?version=1.0. Cited 8 Jan 2018

19. EUROSTAT. Guide to statistics in European Commission development cooperation 2017 edition. Luxembourg: Publications Office of the European Union; 2017. Available from: https://ec.europa.eu/eurostat/documents/38595 98/8141546/KSGQ-17-002-EN-N.pdf

20. Jones K, Moon G. Medical geography: taking space seriously. Prog Hum Geogr. 1993;17:515-24. Sage PublicationsSage CA: Thousand Oaks, CA. Available from: http://journals.sagepub.com/doi/10.1177/030913259301700405. Cited 25 Feb 2017

21. Arcaya MC, Arcaya AL, Subramanian SV. Inequalities in health: definitions, concepts, and theories. Glob Health Action. 2015;8:27106. Taylor \& Francis. Available from: https://www.ncbi.nlm.nih.gov/pubmed/26112142.

22. OECD. OECD review of policy indicators for Portugal. 2015. Available from: https://www.fct.pt/gabestudosestrategia/OCDE/docs/OECD_Policy_ Indicators_for_Portugal_report.pdf

23. Alexander D, Rigby M, Gissler M, Köhler L, MacKay M. The challenge of compiling data profiles to stimulate local preventive health action: a European case study from child safety. Int J Public Health. 2015;60:449-56. Springer. Available from: http://www.ncbi.nlm.nih.gov/pubmed/25740660. Cited 24 Apr 2017

24. Wilkinson JR, Berghmans L, Imbert F, Ledésert B, Ochoa A, ISARE III Project Team. Health indicators in the European regions: expanding regional comparisons to the new countries of the European Union-ISARE III. Public Health. 2009;123:490-5. Elsevier. Available from: http://www.ncbi.nlm.nih gov/pubmed/19615705. Cited 12 Dec 2016

25. Burgard SA, Chen PV. Challenges of health measurement in studies of health disparities. Soc Sci Med. 2014;106:143-50. Elsevier. Available from: http://www.ncbi.nlm.nih.gov/pubmed/24561776. Cited 14 Feb 2017

26. Verschuuren M, Gissler M, Kilpeläinen K, Tuomi-Nikula A, Sihvonen A-P, Thelen J, et al. Public health indicators for the EU: the joint action for ECHIM (European Community Health Indicators Monitoring). Arch Public Health. 2013;71:12. BioMed Central. Available from: http://www.ncbi.nlm.nih.gov/ pubmed/23721296. Cited 5 Jan 2017

27. Rosenkötter N, van Bon-Martens MJH. Public Health Monitoring and reporting: maintaining and improving the evidence-base. Eurohealth Inc Euro Obs. 2015;21:17-20. Available from: http://www.euro.who.int/en/ aboutus/partners/observatory/publications/eurohealth/previous-issues/ reducing-inequalities-in-health-and-health-care

28. Kramers PG. The ECHI project: health indicators for the European Community. Eur J Public Health. 2003;13:101-6. Oxford Journals. Available from: http://www.ncbi.nlm.nih.gov/pubmed/14533758

29. Bilheimer LT, Klein RJ. Data and measurement issues in the analysis of health disparities. Health Serv Res. 2010;45:1489-507. Health Research \& Educational Trust. Available from: http://www.ncbi.nlm.nih.gov/pubmed/21 054368. Cited 25 Feb 2017

30. Stern S, Wares A, Hellman T. Social progress index 216-methodological report; 2016. Available from: https://www.socialprogress.org/assets/ downloads/resources/2016/2016-Social-Progress-Index-Methodology.pdf

31. Wang RY, Storey VC, Firth CP. A framework for analysis of data quality research. IEEE Trans Knowl Data Eng. 1995;7:623-40. Available from: http://ieeexplore.ieee.org/document/404034/. Cited 15 Dec 2016

32. Cai $L$, Zhu $Y$. The challenges of data quality and data quality assessment in the big data era. Data Sci J. 2015;14:2. Ubiquity Press. Available from: http:// datascience.codata.org/article/10.5334/dsj-2015-002/. Cited 15 Dec 2016

33. Askham N, Cook D, Doyle M, Fereday H, Gibson M, Landbeck U, et al. The six primary dimensions for data quality assessment. Group, DAMA UK Work. 2013. Available from: https://www.dqglobal.com/wp-content/uploads/2 013/11/DAMA-UK-DQ-Dimensions-White-Paper-R37.pdf 
34. World Health Organization. Improving data quality: a guide for developing countries. Geneva: WHO Library Cataloguing in Publication Data; 2003.

35. Cassidy M. Assessing gaps in indicator availability and coverage. 2013. Available from: http://unsdsn.org/wp-content/uploads/2014/07/ Assessing-Gaps-in-Indicator-Availability-and-Coverage.pdf

36. Kilpelä Inen K, Tuomi-Nikula A, Rgen Thelen J, Gissler M, Sihvonen A-P, Kramers $P$, et al. Health indicators in Europe: availability and data needs. Eur. J. Public Health. 2011 Oct;22(5): 716-21. Oxford Journals. Available from: https://www.ncbi.nlm.nih.gov/pubmed/22294775

37. Godderis L, Johannik K, Mylle G, Bulterys S, Moens G. Epidemiological and performance indicators for occupational health services: a feasibility study in Belgium. BMC Public Health. 2014 Sep 19;14:410. BioMed Central. Available from: https://www.ncbi.nlm.nih.gov/pubmed/25236590

38. UNIPHE team. Use of sub-national public expenditure on (UNIPHE) WP4 — updated core set of Indicators report (D1). 2008. Available from: https://webgate.ec.europa. eu/chafea_pdb/assets/files/pdb/20081304/20081304_d01_en_ps.pdf

39. FNORS. Health indicators in the European regions. Final report. 2004

40. Fuhr A, Bardehle D, Monch M. CMIS: common minimum indicator set WHO Europe: regions for health network. Final report 2000; 2000. Available from: https://www.Izg.nrw.de/_php/login/dl.php?u=/_media/pdf/service/Pub/wr/ wr15_cmisreport.pdf

41. Liu S, Wilkes A, Li Y, Gao Q, Wan Y, Ma X, et al. Contribution of different sectors to developed countries' fulfillment of GHG emission reduction targets under the first commitment period of the Kyoto Protocol. Environ Sci Policy. 2016;61:143-53. Elsevier. Available from: http://www.sciencedirect. com/science/article/pii/S1462901116300909. Cited 19 May 2017

42. Farchi S, Molino N, Giorgi Rossi P, Borgia P, Krzyzanowski M, Dalbokova D, et al. Defining a common set of indicators to monitor road accidents in the European Union. BMC Public Health. 2006;6:183. Available from: https:// bmcpublichealth.biomedcentral.com/articles/10.1186/1471-2458-6-183

43. Doling J. A European Housing Policy? Int J Hous Policy. 2006;6:335-49. Taylor \& Francis Group. Available from: https://www.tandfonline.com/doi/ full/10.1080/14616710600973169. Cited 3 May 2017

44. De Witte K, Nicaise I, Lavrijsen J, Van Landeghem G, Lamote C, Van Damme J. The impact of institutional context, education and labour market policies on early school leaving: a comparative analysis of EU countries. Eur J Educ. 2013:48:331-45. Wiley. Available from: https://onlinelibrary.wiley.com/doi/ full/10.1111/ejed.12034

45. Lawn M, Rinne R, Grek S. Changing spatial and social relations in education in Europe. In: Ozga J, Dahler-Larsen P, Segerholm C, Simola H, editors. Fabr. Qual. Educ. Data Gov. Eur. New York: Routledge; 2011. Available from: https://www.taylorfrancis.com/books/e/9780203830741/chapters/10.4324/ 9780203830741-10

46. Fehr A, Lange C, Fuchs J, Neuhauser H, Schmitz R. Health monitoring and health indicators in Europe. J Heal Monit. 2017;2. Robert Koch Institut. Available from: http://edoc.rki.de/oa/articles/reZ6OLMSdlmyQ/PDF/23 9ufPuDm2rO.pdf. Cited 3 May 2017

47. Atkinson AB, Marlier $E$, Nolan B. Indicators and targets for social inclusion in the European Union. J Common Mark Stud. 2004:42:47-75. Blackwell Publishing Ltd. Available from: http://doi.wiley.com/10.1111/j.0021-9886.2 004.00476.x. Cited 2 May 2017

48. O'Connor JS. Policy coordination, social indicators and the social-policy agenda in the European Union. J Eur Soc Policy. 2005;15:345-61. Sage PublicationsSage CA: Thousand Oaks, CA. Available from: http://journals. sagepub.com/doi/10.1177/0958928705057289. Cited 2 May 2017

49. Davoine L, Erhel C, Guergoat-Lariviere M. Monitoring quality in work: European employment strategy indicators and beyond. Int Labour Rev. 2008;147:163-98. Blackwell Publishing Ltd. Available from: http://doi.wiley. com/10.1111/j.1564-913X.2008.00030.x. Cited 27 Dec 2017

50. Wilkinson J, Berghmans L, Imbert F, Ledésert B, Ochoa A. Health indicators in the European regions_ISARE II. Eur J Public Health. 2008;18:178-83. Oxford Journals. Available from: http://www.ncbi.nlm.nih.gov/pubmed/17766265

51. Braun T, Bryant G, Bradford C, Wilkinson J. P1-100 I2SARE (indicateurs de santE dans les regions d'Europe) European regional health profiles. J Epidemiol Community Heal. 2011;65:A94-5. BMJ Publishing Group Ltd. Available from: http://jech.bmj.com/cgi/doi/10.1136/jech.2011.142976c.93. Cited 12 Dec 2016

52. Hill A, Balanda K, Galbraith L, Greenacre J, Sinclair D, Observatories A of PH, et al. Profiling health in the UK and Ireland. Public Health. 2010;124:253-8. Elsevier. Available from: http://www.ncbi.nlm.nih.gov/pubmed/20462616. Cited 12 Dec 2016
53. Becker SO, Egger PH, Munich L, Maximilian von Ehrlich. Going NUTS: the effect of EU structural funds on regional performance. 2009; Available from: http:// www20.iadb.org/intal/catalogo/PE/2012/11124a08.pdf. Cited 22 Dec 2017

54. Freitas Â, Santana P, Oliveira MD, Almendra R, Bana e Costa JC, Bana e Costa CA. Indicators for evaluating European population health: a Delphi selection process. BMC Public Health. 2018;18(1).

55. Kindig D, Stoddart G. What is population health? Am J Public Health. 2003;93: 380-3. American Public Health Association. Available from: https://www.ncbi. nlm.nih.gov/pmc/articles/PMC1447747/pdf/0930380.pdf. Cited 18 Apr 2017

56. Kindig DA. Understanding population health terminology. Milbank Q. 2007; 85:139-61. Wiley. Available from: http://www.ncbi.nlm.nih.gov/pubmed/1 7319809. Cited 3 Jan 2017

57. Remington PL, Catlin BB, Gennuso KP. The county health rankings: rationale and methods. Popul Health Metr. 2015;13:11. BioMed Central. Available from: http://www.ncbi.n/m.nih.gov/pubmed/25931988. Cited 22 May 2017

58. Santana P, Freitas Â, Costa C, Vaz A. Evaluating population health: the selection of main dimensions and indicators through a participatory approach. Eur J Geogr. 2015;6:51-63. European Association of Geographers. Available from: http://www.eurogeographyjournal.eu/articles/EJG040601 EVALUATINGPOPULATIONHEALTHTHESELECTIONOFMAINDIMENSIONSAND INDICATORSTHROUGHAPARTICIPATORYAPPROACH.pdf

59. Stefanik I, Freitas Â, Doetsch J, Santana P. Involving key stakeholders in the EURO-HEALTH. In: Promot. Popul. Heal. equity Eur. from Evid. to policy. Coimbra: Coimbra University Press; 2017. Available from: https:/digitalis.uc.pt/ ptpt/livro/promoting_population_health_and_equity_europe_evidence_policy

60. Rodrigues TC. The MACBETH approach to health value measurement: building a Population Health Index in group processes. Procedia Technol. 2014;16:1361-6. Elsevier. Available from: http://linkinghub.elsevier.com/ retrieve/pii/S2212017314003806. Cited 8 June 2017

61. Bana e Costa CA, De Corte J-M, Vansnick J-C. MACBETH. Int J Inf Technol Decis Mak. 2012;11:359-87. World Scientific Publishing Company. Available from: http://www.worldscientific.com/doi/abs/10.1142/S0219622012400068. Cited 26 Jan 2019

62. Santana P, Costa C, Freitas A A, Stefanik I, Quintal C, Bana e Costa C, et al. Atlas of population health in European Union regions. Coimbra: Imprensa da Universidade de Coimbra; 2017. Available from: https://digitalis.uc.pt/ ptpt/livro/atlas_population_health_european_union_regions

63. Bana e Costa C, Oliveira M, Vieira A. Decision support for multicriteria modelling of the population health index and evaluation, foresight and selection of policies. In: Promot. Popul. Heal. equity Eur. from Evid. to policy. Coimbra: Coimbra University Press; 2017.

64. Bana e Costa C, Correia P, Freitas L, Oliveira M, Rodrigues T, Vieira A. Devising and testing a novel methodology for the evaluation of policies under European population health scenarios. In: Promot. Popul. Heal. equity Eur. from Evid. to policy. Coimbra: Coimbra University Press; 2017.

65. European Commission. In: Brandmüller T, Önnerfors $\AA$, editors. Eurostat regional yearbook 2016. European U. Luxembourg: Publications office of the European Union; 2016. Available from: https://ec.europa.eu/eurostat/web/ products-statisticalbooks/-/KS-HA-16-001

66. Costa C, Santana P, Dimitroulopoulou S, Burstrom B, Borrell C, Schweikart J, et al. Population health inequalities across and within European metropolitan areas through the lens of the EURO-HEALTHY Population Health Index. Int J Environ Res Public Health. 2019;16:836. Multidisciplinary Digital Publishing Institute. Available from: https://www.ncbi.nlm.nih.gov/ pmc/articles/PMC6427561/

67. Friel S, Vlahov D, Buckley RM. No data, no problem, no action: addressing urban health inequity in the 21st century. J Urban Health. 2011;88:858-9. Springer. Available from: http://www.ncbi.nlm.nih.gov/pubmed/21956281. Cited 6 Mar 2019

68. Barsanti S, Salmi L-R, Bourgueil Y, Daponte A, Pinzal E, Ménival S. Strategies and governance to reduce health inequalities: evidences from a crossEuropean survey. Glob Heal Res Policy. 2017;2:18. BioMed Central. Available from: https://www.ncbi.nlm.nih.gov/pmc/articles/PMC5683456/

69. European Commission. The social dimension of the Europe 2020 strategy. 2011. Available from: http://eurohealthnet.eu/sites/ eurohealthnet.eu/files/publications/ BriefingonthereportbytheSPConthesocialdimensionofEU2020.pdf.

70. A Strategy for Europe on Nutrition, Overweight and Obesity related health issues \{SEC(2007) 706\} \{SEC(2007) 707\}. Available from: http://ec.europa.eu/ health/ph_determinants/life_style/nutrition/green_paper/nutrition_gp_rep_ en.pdf. Cited 21 Dec 2017 
71. PHEIAC. Evaluation of the use and impact of the European community health indicators ECHI by member states. 2013. Available from: http:// ec.europa.eu/health/indicators/docs/echi_report_v20131031.pdf

72. Wang L, Zhong B, Vardoulakis S, Zhang F, Pilot E, Li Y, et al. Air quality strategies on public health and health equity in Europe-a systematic review. Int J Environ Res Public Health. 2016;13 Multidisciplinary Digital Publishing Institute (MDPI). Available from: http://www.ncbi.nlm.nih.gov/ pubmed/27918457. Cited 21 Dec 2017

73. European Commission. Towards a European road safety area: policy orientations on road safety 2011-2020. Brussels: European Commission, 2010. Available from: https://ec.europa.eu/transport/road_safety/sites/ roadsafety/files/pdf/com_20072010_en.pdf

74. Roth F, Gros D. The post-2010 Lisbon process: the key role of education in employment and competitiveness. SSRN Electron J. 2008; Available from: http://www.ssrn.com/abstract=1334621. Cited 21 Dec 2017

75. Judge K, Platt S, Costongs C, Jurczak K. Health Inequalities: a challenge for Europe. 2006. Available from: http://www.disuguaglianzedisalute.it/wpcontent/uploads/2015/05/Judge-Health-inequalities-A-challenge-for-Europe. pdf. Cited 3 May 2017.

76. Kona a, Melica G, Koffi Lefeive B, lancu A, Zancanella P, Rivas Calvete S, Bertoldi $P$, Janssens-Maenhout G, Monforti-Ferrario F. Covenant of mayors: greenhouse gas emissions achievements and projections. Jt. Res. Cent. Sci. Hub. 2016. Available from: https://ec.europa.eu/jrc/en/publication/eurscientific-and-technical-research-reports/covenant-mayors-greenhouse-gasemissions-achievements-and-projections

77. Atkinson T, Cantillon B, Marlier E, Nolan B. Social indicators: the EU and social inclusion; 2002. Oxford University Press. Available from: http://www. oxfordscholarship.com/view/10.1093/0199253498.001.0001/acprof-97801 99253494. Cited 2 May 2017.

78. INTERREG IVC. Policy recomendations for tackling climate change. Lille; 2014. Available from: http://www.fedarene.org/wp-content/uploads/2016/ 05/Policy-recommendations.pdf

79. World Health Organization. New frontiers in health information and evidence. The European health report 2015. 2015. Available from: http:// www.euro.who.int/_data/assets/pdf_file/0003/288651/European-healthreport-2015-chapter4.pdf?ua=1

80. European Commission. Environmental Noise Directive. Directive 2002/ 49/EC. Off. J. L 189, 18/07/2002 P. 0012 - 0026; OPOCE; 2002. Available from: http://eur-lex.europa.eu/legal-content/EN/TXT/HTML/?uri=CELEX:32 002L0049\&from $=$ EN

81. Panagos P, Van Liedekerke M, Yigini Y, Montanarella L. Contaminated sites in Europe: review of the current situation based on data collected through a European network. J Environ Public Health. 2013;2013:158764. Hindawi Publishing Corporation. Available from: http://www.ncbi.nlm.nih.gov/ pubmed/23843802. Cited 6 June 2017

82. Quevauviller P. Adapting to climate change: reducing water-related risks in Europe-EU policy and research considerations. Environ Sci Policy. 2011;14: 722-9. Elsevier. Available from: https://www.sciencedirect.com/science/ article/pii/S1462901111000219. Cited 6 June 2017

\section{Ready to submit your research? Choose BMC and benefit from:}

- fast, convenient online submission

- thorough peer review by experienced researchers in your field

- rapid publication on acceptance

- support for research data, including large and complex data types

- gold Open Access which fosters wider collaboration and increased citations

- maximum visibility for your research: over $100 \mathrm{M}$ website views per year

At BMC, research is always in progress.

Learn more biomedcentral.com/submissions 